\title{
Microscopy101
}

\section{Correcting Astigmatism in SEM Images}

\author{
Charles E. Lyman
}

Department of Materials Science and Engineering, 5 East Packer Avenue, Lehigh University, Bethlehem, PA 18018

charles.lyman@lehigh.edu

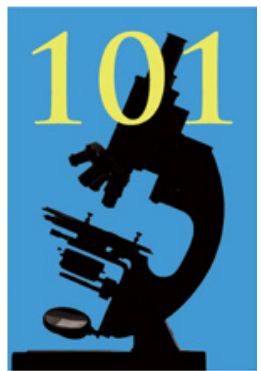

Every scanning electron microscope (SEM) operator should be able to correct an astigmatic image manually. While many SEMs are now equipped with automated astigmatism correction, there are situations, particularly at high magnification, where there is no substitute for eye-hand coordination to make this important correction. There are many ways to correct for astigmatism manually; this article presents the author's preferred technique.

The goal is to make the focused electron probe as small as possible. To view the effect of astigmatism on the image, produce a live image on the SEM viewing screen of a specimen with tiny, random, equiaxed details (no linear features). Linear features tend to fool the eye and cause an incorrect setting of the stigmators. Set the magnification to a high value where the fine details of the random features can be easily viewed (see Figure 1). This may be $5,000 \times$ to $10,000 \times$ for a tungsten (W) gun SEM and $50,000 \times$ to $100,000 \times$ for a field emission gun (FEG) SEM. If available, switch to reduced raster scan so that an image feature can be focused in real time. The presence of astigmatism can be detected by underfocusing the objective lens, causing the image details to line up with the beam shape at that focus. By overfocusing, these details line up along a direction orthogonal to that of the
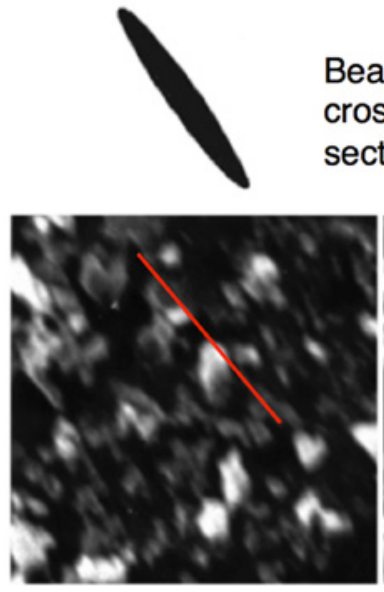

Underfocus

(Knob counter-clockwise)
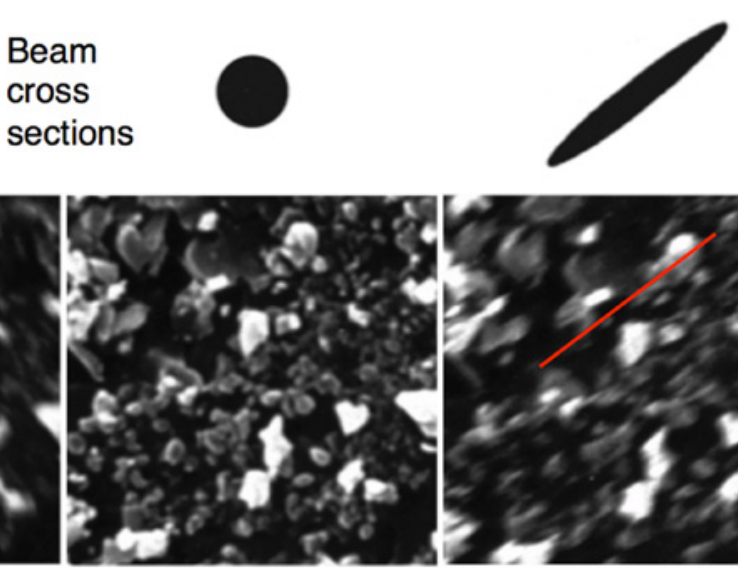

Astigmatic image

(Exact focus)

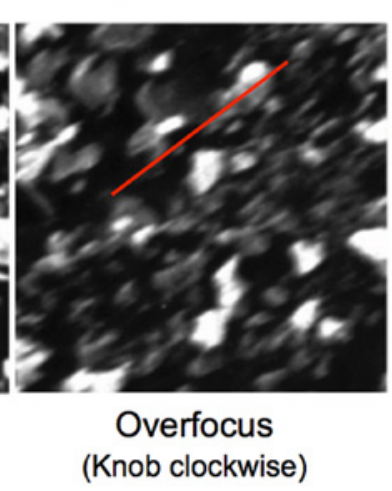

(Knob clockwise)
Figure 1: Through-focus images showing the stretching of the beam in orthogonal directions as the objective lens is first under-focused, brought to exact focus, and then over-focused. The out-of-focus images of particles are aligned with the shape of the elongated electron beam. At exact focus the image of random particles appears to be acceptable, but it is not. Image width $=12 \mu \mathrm{m}$. underfocus condition. At exact focus the image appears to be acceptable, but it is not really as sharp as it could be because the probe size is larger than it should be. Without correcting for astigmatism, the smallest electron probe for that particular condenser lens setting will not have been achieved.

To correct for astigmatism, the operator should find these steps helpful: (1) set the magnification to a high value such that the astigmatism can be detected, typically a step or two higher than that planned for image acquisition; (2) switch to rapid scan with a reduced raster; (3) set the objective lens at the best focus (exact focus) as shown in Figure 1; (4) sharpen the image with the x-stigmator control; (5) refocus the image with the objective lens control; (6) sharpen the image with the y-stigmator; (7) re-focus the image; and (8) repeat steps 4 through 7 until the image cannot be further improved. Figure 2 shows the effect of removing astigmatism from the image: the image shows finer details because the probe size is smaller. Once the focus and stigmation are set at high magnification, these settings will be valid at all lower magnifications.

If the image is noisy or of low contrast, not enough electron probe current was available in the specimen to produce a smooth, noise-free image. To mitigate noise in recorded images, the dwell time of the beam on each pixel could be increased, lengthening the image recording time. Another way to provide more current in the electron probe is to weaken the condenser lens a bit, which will also increase the probe size. But for low and medium magnifications, the larger current and resulting greater contrast will outweigh the increase in electron probe size (for probe sizes $<2$ pixels at the specimen). These are changes to operating conditions that SEM operators might make multiple times in a single session if both low- and high-magnification images are required. With a field-emission electron source such situations are less likely because the electron probe typically will have a large current even at small probe sizes.

Incomplete astigmatism correction can be caused by the following: stigmating at the same magnification used for image acquisition, stigmating on non-random specimen 


\section{Kammrath Weiss}

Islip, USA / Dortmund, Germany

Phone: +1 516-313-9742

Email: sales@kammrath-weiss.com

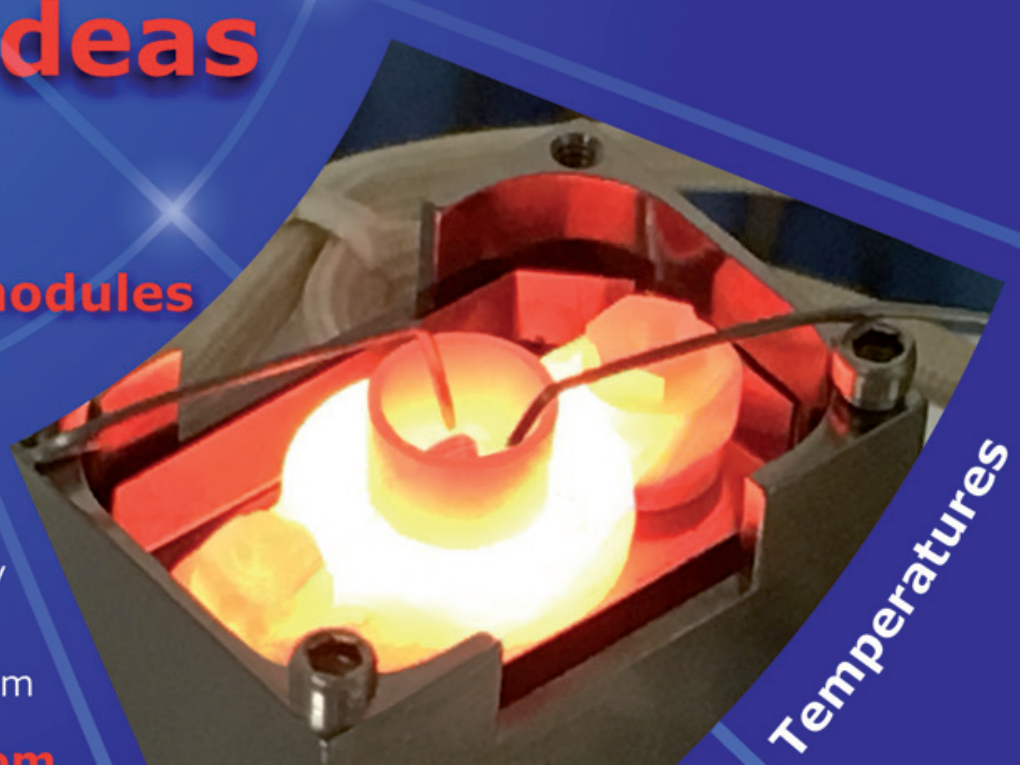

www.kammirath-weiss.com

\section{Don't track dirt on your sample! Use Evactron plasma cleaning}

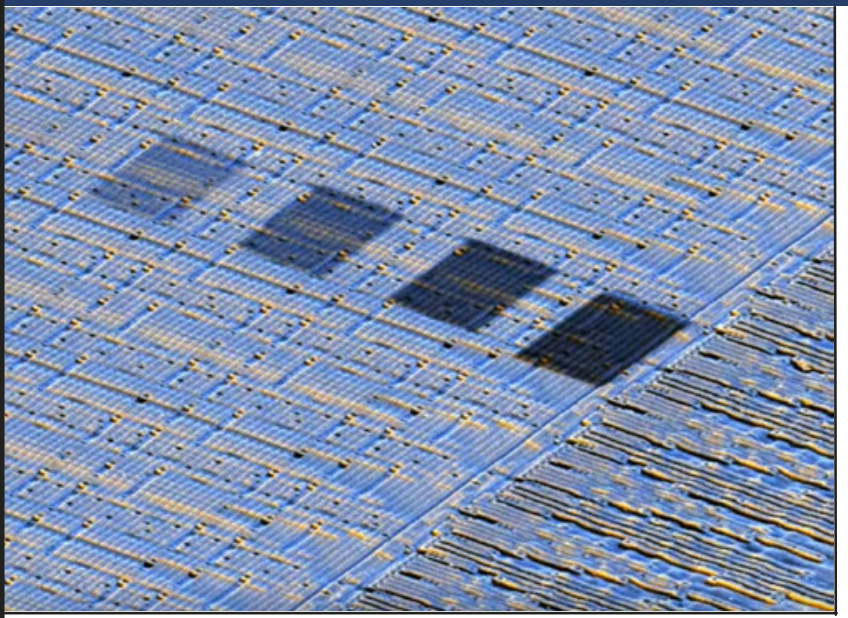

Don't let contaminated chambers and dirty specimens terminate your microscope session. Dual action turbo plasma cleaning ${ }^{T M}$ removes adventitious hydrocarbons with:

* Plasma etch plus UV active desorption

* Hollow cathode plasma radical source

* No sputter etch damage or debris

* A compact and efficient plasma source

* Cleaning in minutes for days of perfect imaging and analysis

Need clean sample and chamber surfaces? Let us show you the "fastest way to pristine" тм ! 

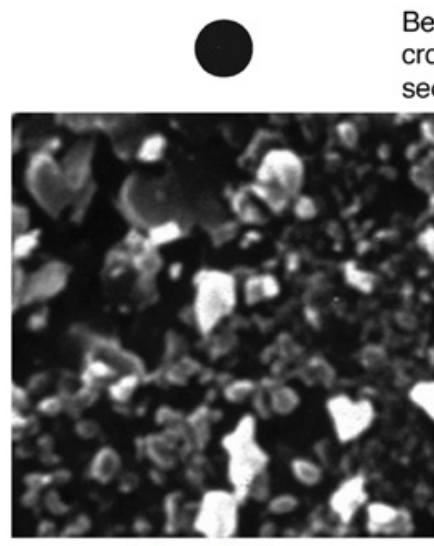

Astigmatic image (Exact focus)
Beam

cross sections

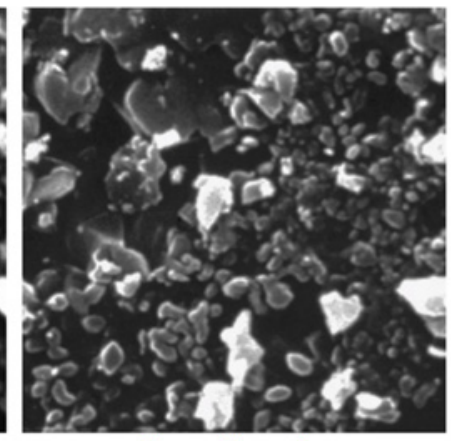

Non-astigmatic (Exact focus)

Figure 2: Images before and after astigmatism correction. At exact focus the astigmatic electron probe is larger than after correction when the contribution to the probe size attributable to astigmatism is eliminated. Image width $=10 \mu \mathrm{m}$.

details, and just using the focus and stigmator controls to sharpen the image without a strategy [1].

\section{Reference}

[1] JI Goldstein et al., Scanning Electron Microscopy and X-ray Microanalysis, $2^{\text {nd }}$ edition, Plenum-Springer, New York, 1992.

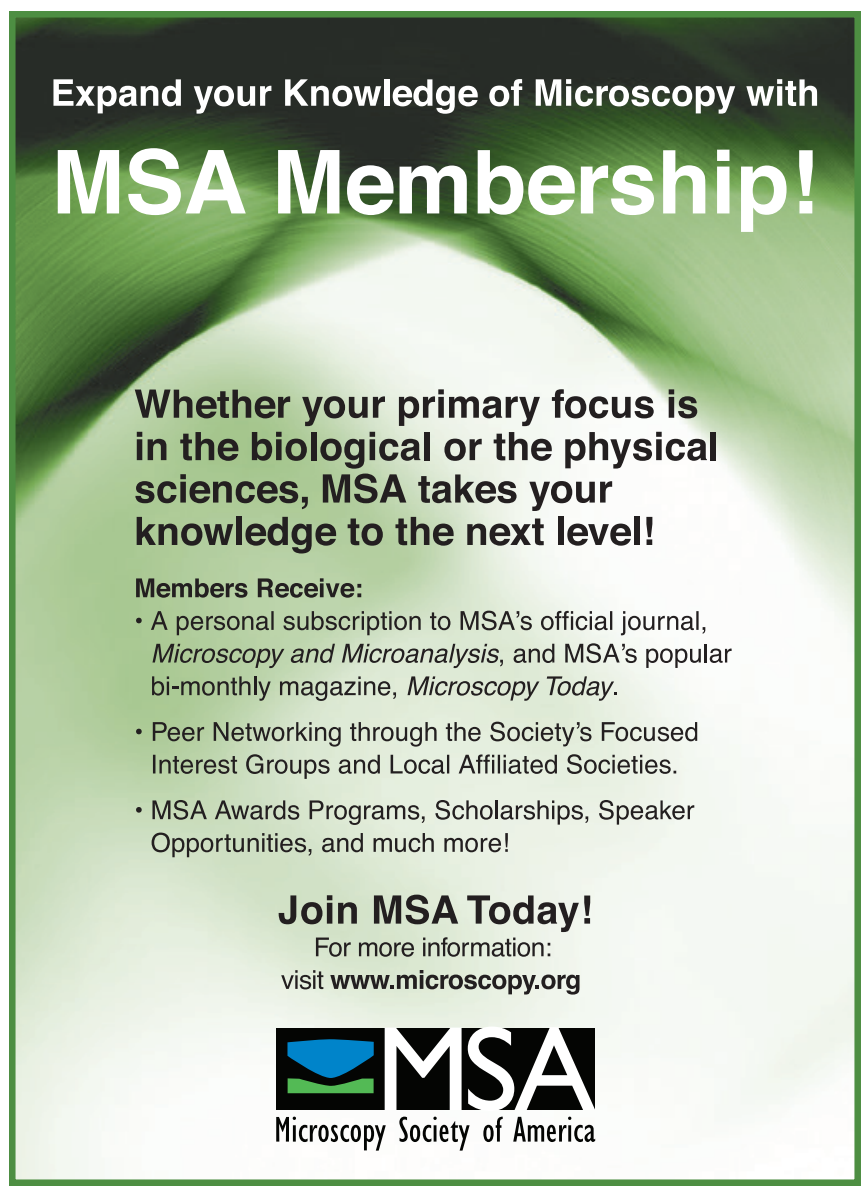

Whether your primary focus is in the biological or the physical sciences, MSA takes your knowledge to the next level!

Members Receive:

- Peer Networking through the Society's Focused Interest Groups and Local Affiliated Societies.

- MSA Awards Programs, Scholarships, Speaker

\section{Join MSA Today!}

For more information:

visit www.microscopy.org

Microscopy Society of America

\section{5th Interamerican Microscopy Congress CIASEM 2019}

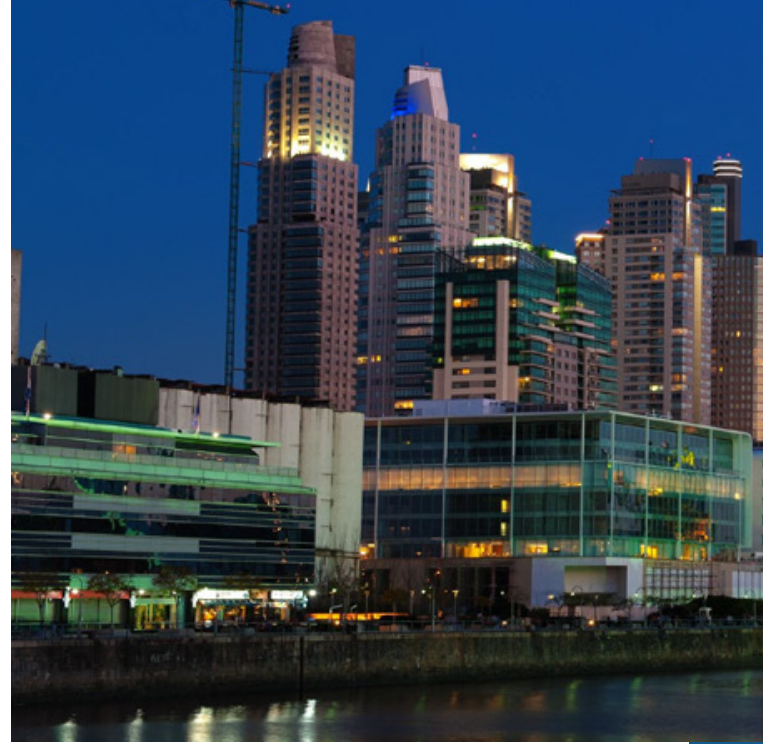

O0:
00 SAMIC - ASOCIACIÓN
Buenos Aires, Argentina

October 1-4, 2019
Abstract submission opens soon, check our website! wWw.ciasem2019.samic-argentina.org 


\section{MINITOOL}

Precision Micro-Tools

Efficient, precise and realistically proportioned
instruments are ideal for microscopists. Our
line of micro-tools includes needles, gravers,
chisels, knives, hooks and mirrors, probes,
spatulas, scribes and microrulers.
All 32 tools are offered singly or in sets of eight
tools with handles. Available in tip diameters
from .025mm to 1.00mm.
www.minitoolinc.com
info@minitoolinc.com

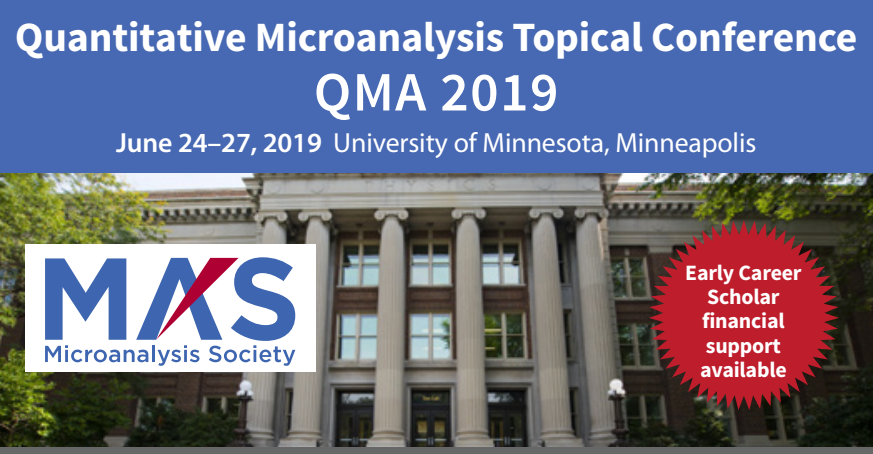

Improve your microanalysis skills, meet new people, and learn from the experts

SCIENTIFIC PROGRAM

Quantitative WDS and EDS microanalysis • FE-EPMA and SEM • Microanalysis standards • Compositional mapping • Quality control • Sample preparation $\cdot$ Hardware developments $\cdot$ Microanalysis applications $\cdot \mathrm{CL}$ and Soft X-ray spectroscopy • Early Career Scholar presentations - Sponsor technical presentations GROUP SESSIONS

Tutorials $•$ User group meetings $\cdot$ Problem solving $\cdot$ Microanalysis software tools and demonstrations

SCIENTIFIC AND SOCIAL EVENTS

Opening reception - Group meals and banquet • Poster session • Networking opportunities

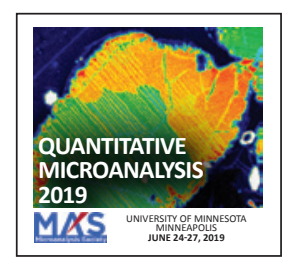

\section{PELCO'silicon Nitride} \& Silicon Dioxide Membranes

Next Generation SiN TEM Support Films

- Robust and clean 8, 15, 50 and $200 \mathrm{~nm}$ SiN substrates

- ø3.0mm frame

- EasyGrip ${ }^{\mathrm{tw}}$ edges

- Free from debris

- Super flat 8, 15, and 40nm silicon dioxide substrates

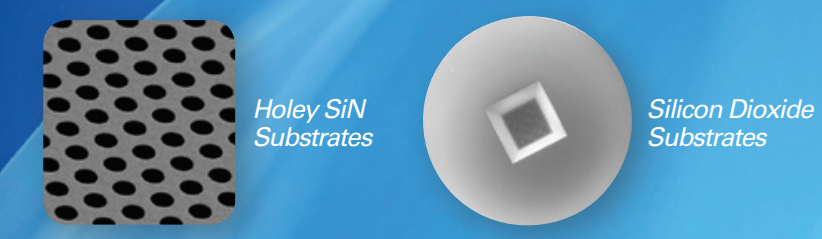

$$
\begin{aligned}
& \text { TED PELLA, ING, } \\
& \text { Microscopy Products for Science and Industry }
\end{aligned}
$$

www.tedpella.com sales@tedpella.com 800.237.3526

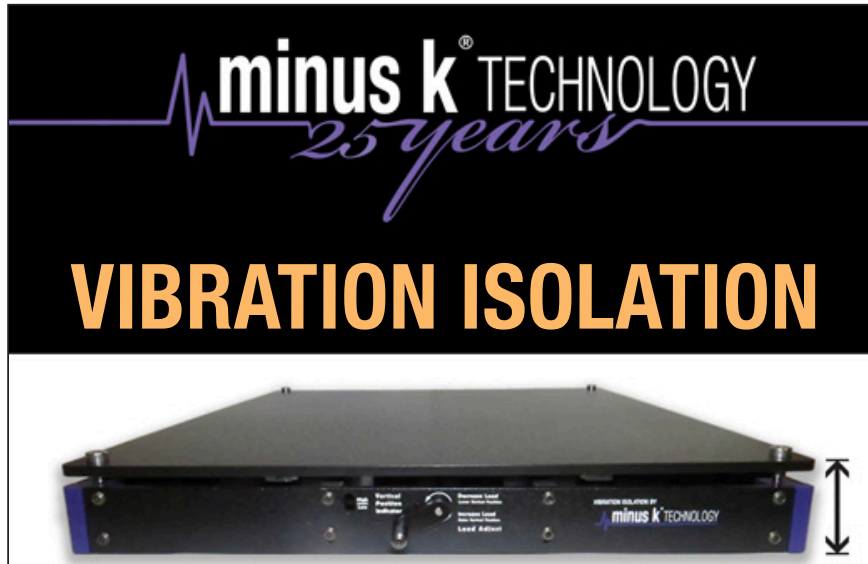

Now only $21 / 4$ inches tall

BREAKTHROUGH

Ultimate $0.5 \mathrm{~Hz}$ Performance!

Perfect for Microscopes

No Air! No Electricity!

sales@minusk.com

www.minusk.com 